\title{
Static analysis of transmission tower beam structure
}

\author{
Lenka Jakubovičová1,*, Alžbeta Sapietová ${ }^{1}$, Jan Moravec $^{1}$ \\ ${ }^{1}$ University of Žilina, Faculty of Mechanical Engineering, Department of Applied Mechanics, \\ Univerzitná 8215/1, Žilina, Slovakia
}

\begin{abstract}
The main topic of this paper is a static analysis of transmission tower beam structure fixed to the earth. It contains facts necessary for a need to create and apply tower beam structures. Beam elements were used to design a model and a static analysis was performed in finite element program Ansys Workbench. Three types of analyses were applied. The modal analysis was applied to verify the model compatibility. The static analysis was applied to find maximal deformations and the bending moment caused by overhead conductors and self-weight. Eigenvalue buckling was applied to state a loss of stability. Finally, stability and suitability of the whole construction was considered.
\end{abstract}

Keywords: modal analysis, Eigenvalue buckling, FEM, Ansys Workbench

\section{Introduction}

The historical development itself required an origin and a beginning of application of power line pylons for electric power transmission [1]. The first transmission of electricity over long distances was performed by the scientist Stephen Gray and his friend Granville Wheeler in the 18th. century. A distance of transmission was 765 feet, which is around 230 metres. In 1891 the first transmission network of three-phase alternating current took place during the international electricity exhibition in Frankfurt. Miller together with his colleague M.O. Dolivo-Dobrovolskij and other professionals were able to construct a network of the length of 110 miles (around $177 \mathrm{~km}$ ) from town Lauffen to Frankfurt.

Current was transmitted by means of copper wires in a three-phase alternating current system with the efficiency around $75 \%$. At the beginning of the 20th century, first $110 \mathrm{kV}$ and later $220 \mathrm{kV}$ facilities were constructed. Hand in hand with increasing needs for transmission of energy there was an increase in needs for static and mechanical stability of transmission structures.

Transmission structures have various constructions and application follows needs for their operation, placement in a ground, a type of tension and transmitted volume of electrical energy. Tower bodies usually have quadrangular structures with a constant or linearly varying cross section. In the submitted paper we analyze a standard high voltage transmission tower concreted in the base [2].

\footnotetext{
*Corresponding author: lenka.jakubovicova@fstroj.uniza.sk

Reviewers: Wieslawa Piekarska, Robert Grega
} 


\section{Finite element model}

\subsection{Cross Sections}

A model of the high voltage transmission tower is a beam structure. Each beam is of a different profile (tab. 1, tab. 2). In general, in the structure there are used seven different profiles of the shape "L" (fig.1) and "U" (fig.2). A principle to design a model of the transmission tower consists in a fact that individual beams are presented as lines in the structure (fig. 4) and they form a beam structure together. Each line represents a concrete beam to which a profile is assigned and, thus, also properties belonging to the profile.

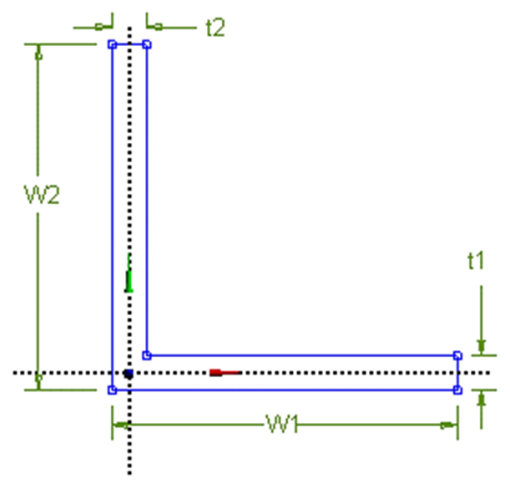

Fig. 1 Dimensions of L profile

Table 1 - Table of dimensions of applied L profiles

\begin{tabular}{|c|c|c|}
\hline \multirow{2}{*}{ Profile } & \multicolumn{2}{|c|}{ Dimension of a profile quote in [mm] } \\
\cline { 2 - 3 } & W1=W2 & $\mathbf{t 1}=\mathbf{t} 2$ \\
\hline R150k15 & 150 & 15 \\
\hline R130k12 & 130 & 12 \\
\hline R120k10 & 120 & 10 \\
\hline U60k5 & 60 & 5 \\
\hline U50k4 & 50 & 4 \\
\hline U35k4 & 35 & 4 \\
\hline
\end{tabular}

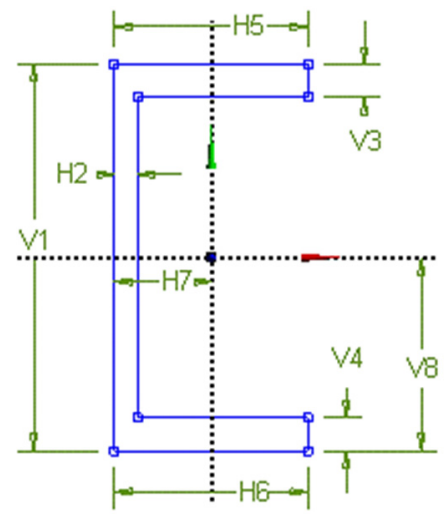

Fig. 2 Dimensions of profile U100 
Table 2 Dimensions of profile U100

\begin{tabular}{|c|c|c|c|c|c|c|c|c|}
\hline \multirow{2}{*}{ Profile } & \multicolumn{8}{|c|}{ Dimension of a profile quote in [mm] } \\
\cline { 2 - 9 } & H2 & H5 & H6 & H7 & V1 & V3 & V4 & V8 \\
\hline U100 & 6 & 50 & 50 & 25 & 100 & 8.5 & 8.5 & 50 \\
\hline
\end{tabular}

\subsection{Boundary conditions}

Electric conductors are attached to consoles of the high voltage transmission tower and they act with their own weight in the point of attachment.

The load of the transmission tower will represent weight of 6 electric conductors attached to consoles together with self-weight of the whole construction. Points of attachment will be in the same heights and, thus, we may assume that we speak of a symmetric field from the both sides [3]. Towers will be spaced a $=100 \mathrm{~m}$ from the both sides. For power transmission will be applied AlFe wire marked 42/25 according to STN 024310 and its parameters together with other parameters necessary for load calculations were calculated according to the publication Mechanics of outdoor power lines[4]. fig.3.

The load calculation was considered according to a condition of the symmetric field in

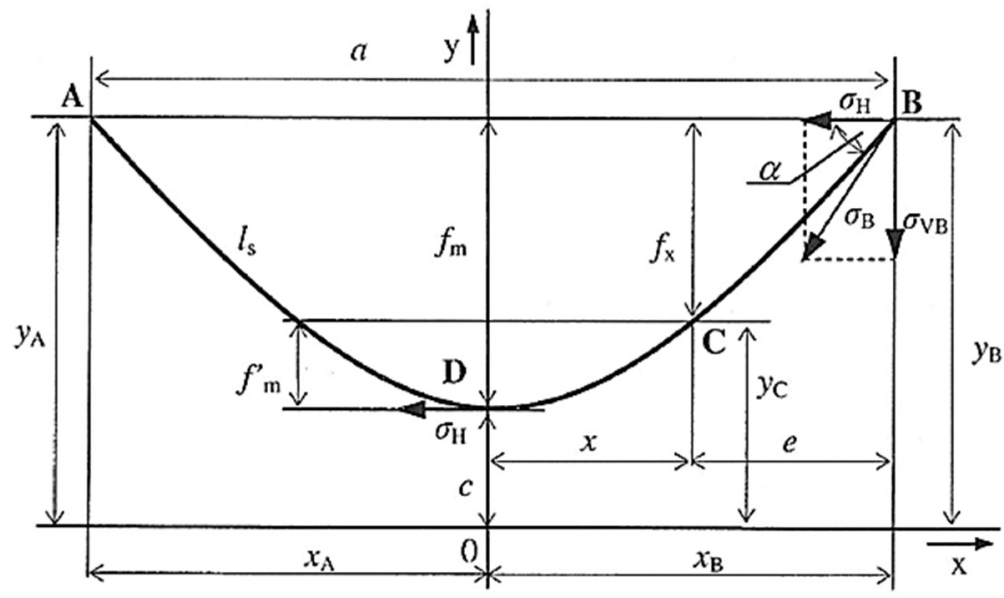

Fig. 3 Symmetric catenary

The parameter of parabola

$$
c=\frac{\sigma_{H}}{\gamma \cdot z}=\frac{177.0315 \cdot 10^{6}}{0.046702 \cdot 10^{6} \cdot 5.9}=642.5 \mathrm{~m} .
$$

The maximum deflection of the catenary

$$
f_{m}=c \cdot\left(\cosh \left(\frac{a_{v}}{2 c}\right)-1\right)=642.5 \cdot\left(\cosh \left(\frac{100}{2 \cdot 642.5}\right)-1\right)=1.9465 m .
$$

Total mechanical stress in the suspension point B from one wire

$$
\sigma_{B}=\sigma_{H} \cdot \cosh \left(\frac{a_{v}}{2 \cdot c}\right)=177.0315 \cdot \cosh \left(\frac{100}{2 \cdot 642.5}\right)=177.567 M P a .
$$

Total force in the suspension point B from one wire

$$
F_{B}=\sigma_{B} \cdot S_{l}=177.567 \cdot 10^{6} \cdot 67.07 \cdot 10^{-6}=11909.48576 \mathrm{~N} .
$$


A vertical force component in the suspension point B

$$
F_{V B}=\sigma_{V B} \cdot S_{l}=13.8 \cdot 10^{6} \cdot 67.07 \cdot 10^{-6}=925.566 \mathrm{~N} .
$$

Total force in the suspension point $F_{B}=11909.5 \mathrm{~N}$ will be applied as a force on 6 suspension points of geometry at the same angle. Three forces will be oriented positively and three negatively, fig. 5.

To obtain the correct orientation of powers it is necessary to distribute force into vector components in Ansys Workbench, fig. 4.

The angle at which the forces act:

$$
\sin \alpha=\frac{F_{V B}}{F_{B}}=0.07774198696=>\alpha=4.459^{\circ} .
$$

Force in the suspension point in the horizontal direction:

$$
F_{H B}=F_{V B} \cdot \cos \alpha=11869.564 N .
$$

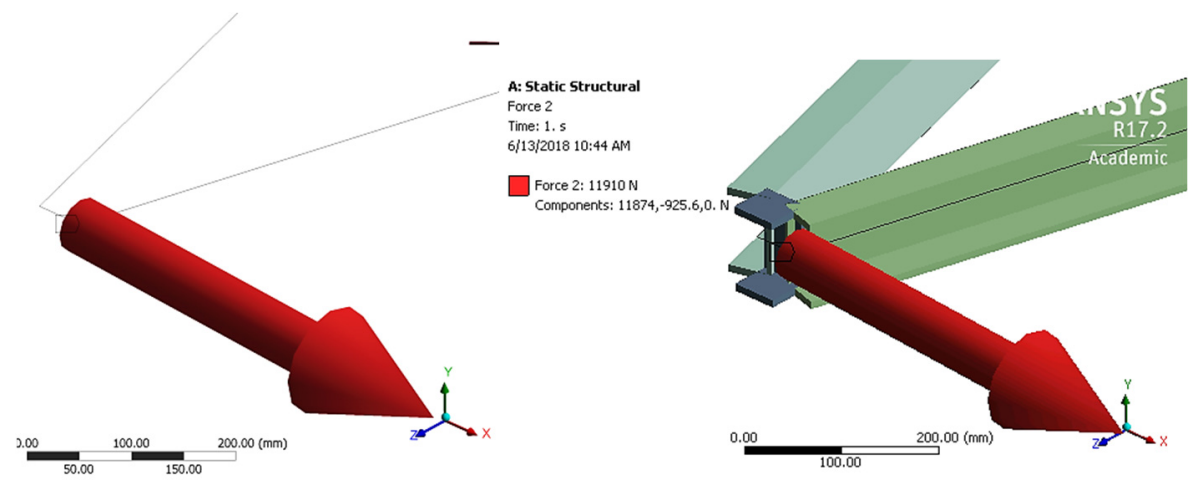

Fig. 4 Force components

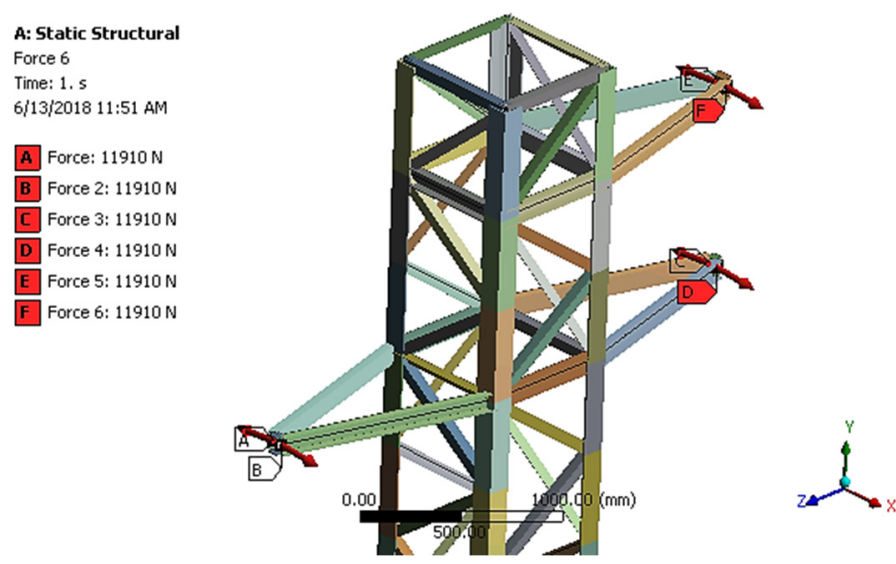

Fig. 5 Load by forces from wires

In figure 6 all degrees of freedom are removed from elements marked in the blue colour. That represents the condition of a concreted section of the transmission tower. 


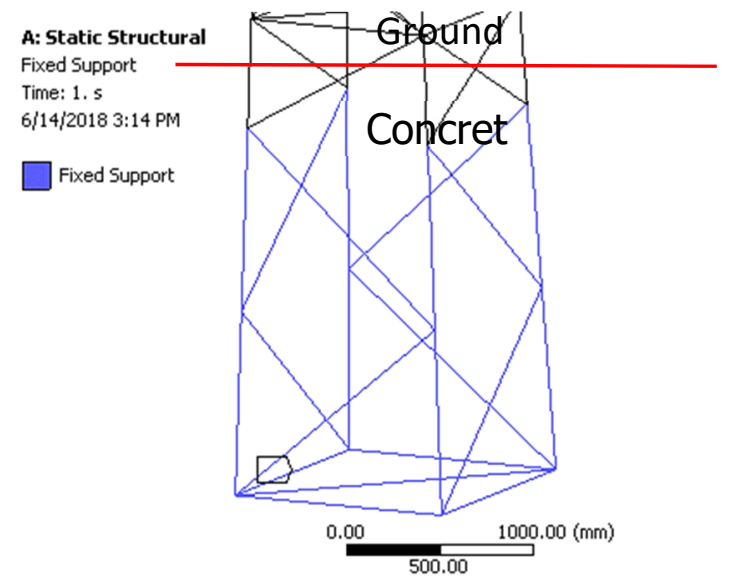

Fig. 6 Boundary condition "Fixed Support"

\section{Analysis}

The modal analysis was applied to control compatibility of the whole model. The first six own frequencies were equal or close to zero and that mean six degrees of freedom for a body $[5,6]$. In a further analysis of the transmission tower we need to pay our attention to a static analysis and a buckling analysis, as we deal with a slim construction [7, 8].

\subsection{Finite-element analysis}

Using this analysis we are able to verify stiffness of construction affected by the load caused by suspension wires and standard gravity force. In figure 7 there is shown total deformation and figure 8 contains Total Bending Moment.

\begin{tabular}{|c|}
\hline 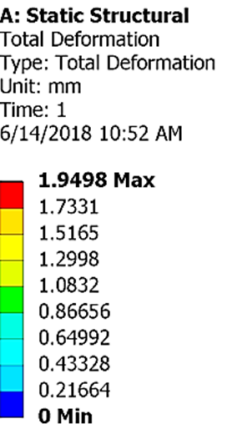 \\
\hline
\end{tabular}

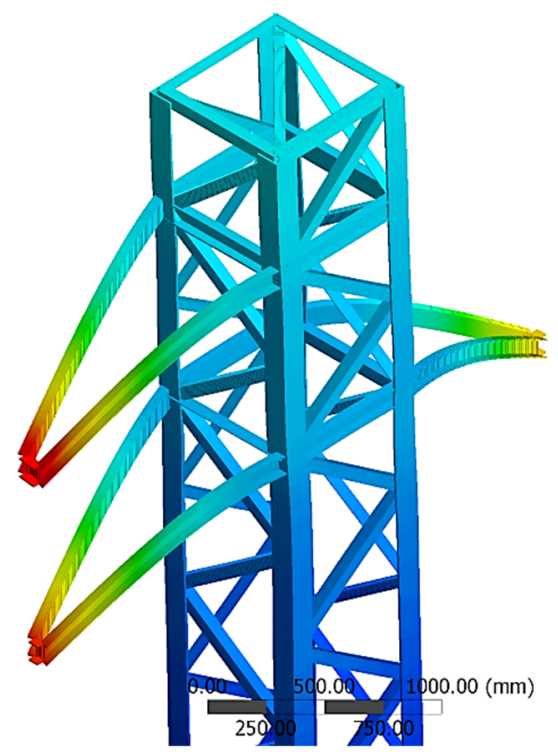

Fig. 7 Total deformation caused by suspension wires 
The maximal value of total deformation according to figure 7 was measured as $1.95 \mathrm{~mm}$. The value of the deformation points to a slight impact of load on a console holder and also on the whole construction.

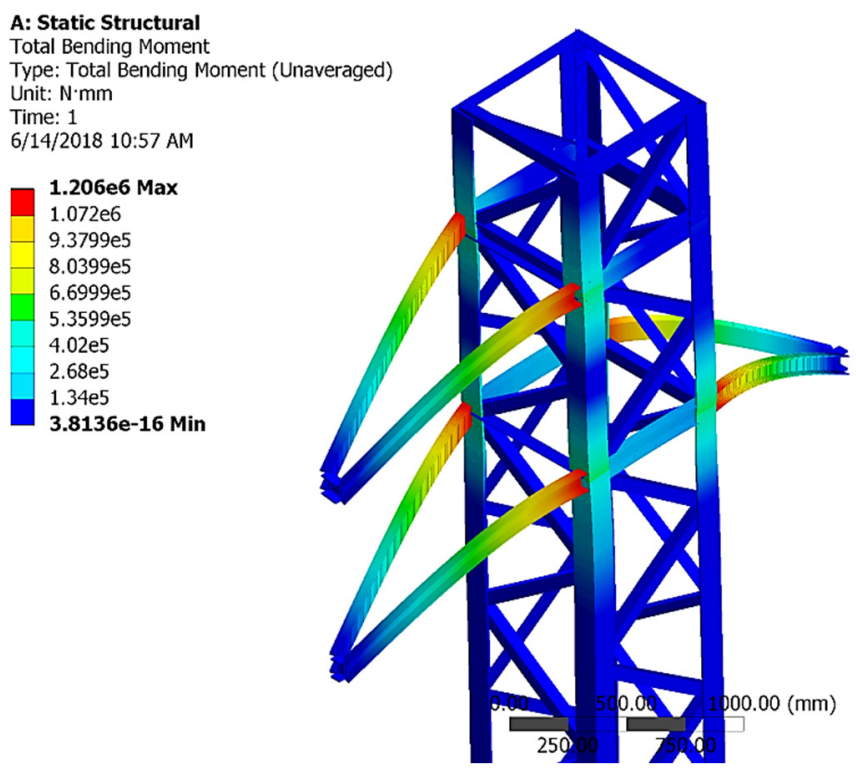

Fig. 8 Total bending moment

Stress in bending in the point with a maximum bending moment will be calculated according to the relation (8).

$$
\sigma_{O M A X}=\frac{M_{O}}{W_{O}}=\frac{1206}{0.000041402287}=29.13 \mathrm{MPa} .
$$

For steel 11503, the maximum allowable stress is $\sigma_{\mathrm{DOV}}=245 \mathrm{MPa}$.

Stress condition together with safety coefficient which includes also ice and icing on wires:

$$
\begin{gathered}
\sigma_{O M A X} \cdot k \leq \sigma_{D O V} \\
29.13 \cdot 4=116.52 \mathrm{MPa}<245 \mathrm{MPa} \Rightarrow \gg \text { allowed. }
\end{gathered}
$$

\subsection{Eigenvalue Buckling}

The third analysis will be an eigenvalue buckling analysis of the transmission tower, as it is a slim construction. This type of analysis provides us information regarding identification of maximum values of load in which a damage of the analyzed structure may occur under the influence of a stability loss $[9,10]$. In Table 3 there are stated the lowest values for a stability loss for a given tower. The first value 7.2388 provides us the information that if we increase the amount of load 7.2388 times, the first case of a stability loss occurs. If we increase load by 11.875 times, the second case of stability occurs. 
Table 3 Results of Eigenvalue Buckling analysis

\begin{tabular}{|c|}
\hline A real load multiplier \\
\hline 7.2388 \\
\hline 11.875 \\
\hline
\end{tabular}

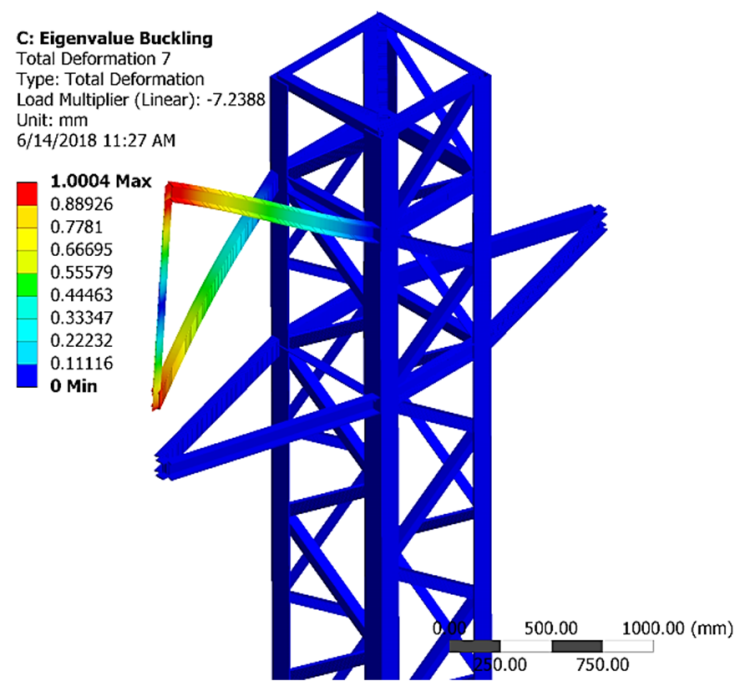

Fig. 9 Total deformation of the first value of a stability loss

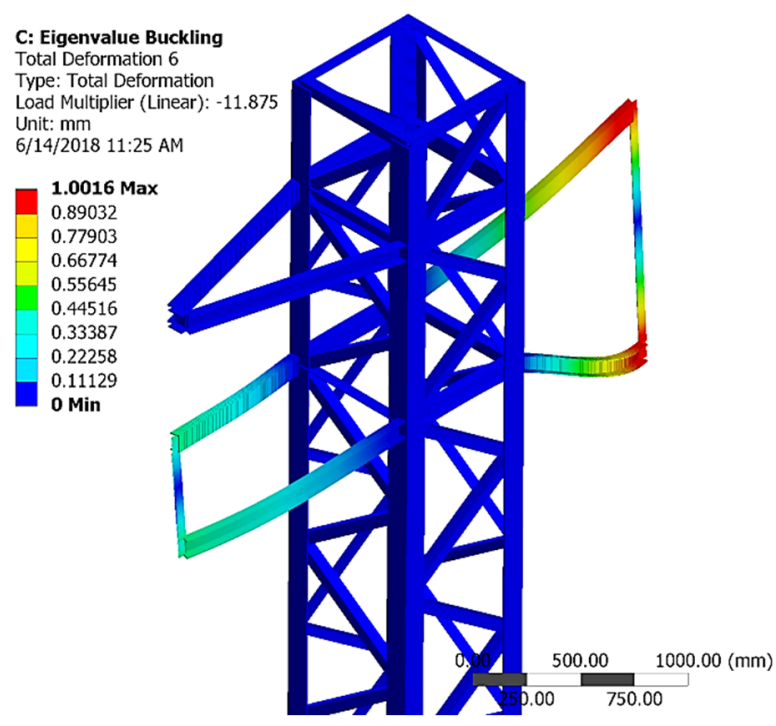

Fig. 10 Total deformation of the second value of a stability loss

Results of the analysis approve that the construction is stable enough by a given load by wires and self-weight. Load acting on the power tower must increase almost sevenfold to cause the first case of a stability loss. From measured results it is also possible to analyze the weakest element of the whole construction which is the console holding wires. 


\section{Summary}

The aim of the work was to prepare a model and to perform a statistic analysis of the transmission tower beam structure that is fixed to the earth. We made three types of different analyses. The first one, a modal analysis, was performed after formation of geometry with the aim to verify a compatibility of the model. The second analysis was a static analysis. Its aim was to find out, respectively verify areas with the highest value of deformation and a bending moment to prevent a stability loss of the whole construction or an element of the power tower (a console for mounting of suspension wires). The third analysis, Eigenvalue buckling, was performed after a meshing and boundary conditions for the model with the aim to identify possible conditions of stability losses.

Finite-element mesh was created and boundary conditions defined. Concreting of the power tower up to the height of 2 metres was represented by a removal of all degrees of freedom to elements that were in concrete. To remove degrees of freedom we used the function "Fixed Support". A size and orientation of load under an influence of suspension wires were calculated according to a presumption of symmetric overhead conductors. The resultant force acting on the suspension point $\mathrm{F}_{\mathrm{VB}}=11905.6 \mathrm{~N}$ was applied on 6 suspension points at the angle of $\alpha=4.459^{\circ}$. The final deformation was measured at the value of $1.95 \mathrm{~mm}$. A very low value of deformation proves the fact that a construction will manage mounting of conductors without any problems. Another evidence of the suitable construction is also a verification by means of strength conditions. The maximum stress is $\sigma_{\text {OMAX }}=29.13$ MPa after multiplication by a safety coefficient $\mathrm{k}=4$, i.e., $29.13 \cdot 4=116.52 \mathrm{MPa}$ is still less that the allowed load $\sigma_{\mathrm{DOV}}=245 \mathrm{MPa}$ for steel used in a construction of transmission power towers.

Results obtained by the finite-element program Ansys Workbench can be considered as approximate. By multiplication by safety coefficient we obtain deformations and bending moments under critical values. An advantage of the process of a solution is its speed and flexibility. In case of a change of applied profiles, we do not need to define the whole geometry from the ground, we just need to allocate a new profile to a selected body.

This work was supported by the Slovak Research and Development Agency under the contract No. APVV-14-0096 and by grant KEGA 015ŽU-4/2017 - Digital technologies for machine building study programs as a part of strategy "Internet of Things".

\section{References}

1. Flizikowski, J., Macko, M.: Method of estimation of efficiency of quasi-cutting of recycled opto-telecommunication pipes. Polimery/Polymers, XLVI, 53-59 (2001)

2. K. J. Bathe, Finite Element Procedures. Prentice Hall, New Jersey (1982)

3. J. Kortis, L. Daniel, M. Handrik, The Numerical Analysis of the Joint of the Steel Beam to the Timber Girder. Procedia Engineering, 91, 160-164, (2014)

4. A. Otčenášová, Mechanika vonkajšich silových vedení. Žilina: University of Zilina EDIS - publisher ŽU.. 236 (2010)

5. R. Grega, J. Krajňák, L. Žul'ová, G. Fedorko, V. Molnár, Failure analysis of driveshaft of truck body caused by vibrations. Engineering Failure Analysis, 79, 208-215 (2017)

6. A. Vasko, M. Vasko, J. Belan, E. Tillova, Comparison of fatigue properties of nodular cast iron at low and high frequency cyclic loading. Procedia Engineering, 177, 576-581, (2017) 
7. W. Piekarska, M. Kubiak, M. Žmindák, Issues in numerical modeling of phase transformations in welded joint. XXI Polish-Slovak Scientific conference machine modeling and simulations MMS 2016, Procedia Engineering, 177, 141-148 (2017)

8. P. Kovacikova, R. Bezdedova, J. Jr.Vavro, J. Vavro, Comparison of numerical analysis of stress-strain states of cast iron with vermicular graphite shape and globular graphite shape. 20 th International conference machine modeling and simulations MMS 2015, Procedia Engineering, 136, 28-32 (2016)

9. M. Handrik, M. Vasko, P. Kopas, V. Mozer, The linear and nonlinear stability loss of structures due to thermal load. Procedia Engineering, 136, 359-364, (2016),

10. L. Zul'ova, R. Grega, J. Krajňák, G. Fedorko, V. Molnár, Optimization of noisiness of mechanical system by using a pneumatic tuner during a failure of piston machine, 79, 845-851, (2017) 